\title{
Osteonecrose Induzida por Bifosfonato em Mandíbula: Relato de Caso
}

\author{
Bisphosphonate-Induced Osteonecrosis in Jaw: Case Report \\ Osteonecrosis Mandibular Inducida por Bisfosfonatos: Reporte de un Caso
}

Maria Santos da SILVA

Acadêmica do curso de graduação em Odontologia, Escola Superior de Ciências da Saúde, Universidade do Estado do AmazonasUEA, 69065-001 Manaus-AM, Brasil Lioney Nobre CABRAL

Professor da Escola Superior de Ciências da Saúde, Universidade do Estado do Amazonas-UEA, 69065-001 Manaus-AM, Brasil, Doutor em Biotecnologia pela Universidade Federal do Amazonas-UFAM https://orcid.org/0000-0002-0505-4070 Antônio Jorge Araújo de VASCONCELOS II Professor da Escola Superior de Ciências da Saúde, Universidade do Estado do Amazonas-UEA, 69065-001 Manaus-AM, Brasil, Mestre em Patologia Bucal pela Universidade do Federal do Amazonas-UFAM https://orcid.org/0000-0001-5947-1438

\section{Resumo}

O uso de bifosfonato está associado com a necrose óssea dos maxilares, condição esta secundária aos mecanismos de ação da droga, resultando em atividades antiosteoclástica e antiangiogênica, alterando o metabolismo ósseo, inibindo a reabsorção e diminuindo a renovação tecidual. Este tem como objetivo relatar um caso de osteonecrose induzida por bifosfonato em área retromolar mandibular de paciente do sexo feminino, 76, portadora de prótese removível que faz uso de Alendronato de sódio há mais de 20 anos para tratamento de Osteoporose. Ao exame intra-oral constatou-se lesão nodular séssil, indolor, consistência mole, forma e superfície irregular, coloração eritematosa em área central, medindo $1,5 \times 0,6 \times 0,5 \mathrm{~cm}$, localizada no rebordo alveolar inferior esquerdo, com quatro meses de evolução. A tomografia mostrou área de reabsorção em taça. Realizou-se biopsia excisional da lesão superficial, aspecto clínico de parúlide e o material foi submetido ao exame histopatológico, onde revelou-se epitélio com áreas hiperplásicas e atróficas, com focos de desorganização por exocitose polimorfonuclear e, no tecido conjuntivo, exsudato fibrinopurulento e necrose coagulativa com cariorrex, além de aglomerados microbianos. Diante da anamnese, exames imagenológicos e histopatológico conseguiu-se associar o diagnóstico clínico da lesão à osteonecrose subjacente, induzida pelo uso do bifosfonato. O tratamento instituído foi remoção cirúrgica da lesão superficial, desgaste protético para o alívio do trauma local e laserterapia de baixa intensidade vermelho e infravermelho $3 \mathrm{~J} / \mathrm{cm}^{2}$ local. Paciente não teve recidiva da lesão após 1 ano e 11 meses do tratamento.

Descritores: Arcada Osseodentária; Difosfonatos; Mandíbula.

\section{Abstract}

The use of bisphosphonate is associated with bone necrosis of the jaws, a condition secondary to the drug's mechanisms of action, resulting in anti-osteoclastic and anti-angiogenic activities, altering bone metabolism, inhibiting resorption and decreasing tissue renewal. This article aims to report a case of bisphosphonate-induced osteonecrosis in the mandibular retromolar area of a 76 years old female patient, user a removable prosthesis who has been using Alendronate sodium for over 20 years for the treatment of osteoporosis. The intraoral examination revealed a sessile nodular lesion, painless, soft consistency, irregular shape and surface, erythematous color in the central area, measuring $1.5 \times 0.6 \times 0.5 \mathrm{~cm}$, located in the lower left alveolar ridge, with four months of evolution. The tomography showed an area of cup resorption. An excisional biopsy of the superficial lesion was performed, showing a clinical appearance of parulide and the material was submitted to histopathological examination, which revealed epithelium with hyperplastic and atrophic areas, with foci of disorganization due to polymorphonuclear exocytosis and, in the connective tissue, fibrinopurulent exudate and necrosis coagulative with kyorrhex, in addition to microbial agglomerates. Based on the anamnesis, imaging and histopathological examinations, it was possible to associate the clinical diagnosis of the lesion with the underlying osteonecrosis, induced by the use of bisphosphonate. The treatment instituted was surgical removal of the superficial lesion, prosthetic wear for the relief of local trauma and local low-intensity red and infrared $3 \mathrm{~J} / \mathrm{cm}^{2}$ laser therapy. The patient had no recurrence of the lesion after 1 year and 11 months of treatment

Descriptors: Jaw; Diphosphonates; Mandible.

\section{Resumen}

El uso de bisfosfonatos está asociado con necrosis óssea de los maxilares, una condición secundaria a los mecanismos de la droga que resulta en atividades anti-osteoclásticas y anti-angiogénicas, alterando el metabolismo ósseo, que inhibe la reabsorción y disminuye la renovación del tejido. Este tiene objetivo reportar un caso de osteonecrosis inducida por bisfosfonatos en la área retromolar mandibular de una paciente de 76 años con prótesis removible que hace uso de Alendronato de sodio durante más de 20 años para tratar la osteoposis. El examen intraoral reveló una lesión nodular sésil, indolora, conscíencia blanda, de forma y superfície regular, eritematoso en la zona central, de $1,5 \times 0,6 \times 0,5 \mathrm{~cm}$, localizada en el reborde alveolar inferior izquierdo, con cuatro meses de evolución. La tomografia computarizada mostró reabsorción de la copa. Se realizó biopsia excisional de la lesión superficial, aspecto clinico de parúlide, y se sometió el material a examen histopatológico, que reveló epitélio con áreas hiperclásicas y atróficas, con focos de desorganización exocitosis polimórfica nuclear y, en el tejido conectivo, exudado fibrinopurulento y cogulación de necrosis con carriorex, además de aglomerados microbianos. A partir de la anamnesis, los exámenes de imagen y histopatológicos, fue posible asociar el diagnóstico clínico de la lesión con la osteonecrosis subyacente, inducida por el uso del bisfosfonatos. El tratamiento instituído fue la extirpación quirúrgica de la lesión superficial, el degaste protésico para aliviar el traumatismo local y la terapia local con laser rojo y infrarrojo de baja intensidad de $3 \mathrm{j} / \mathrm{cm}^{2}$. El paciente no presentó recidiva de la lesión después de 1 año y 11 meses de tratamiento.

Descriptores: Maxilares; Difosfonatos; Mandibula.

\section{INTRODUÇÃO}

\section{A osteoporose é uma doença comum} caracterizada pela baixa densidade e deterioração estrutural do tecido ósseo, dando origem a uma diminuição na resistência deste tecido e maior suscetibilidade à fraturas ${ }^{1}$. A mesma gera grandes custos anualmente devido à alta incidência de fraturas e morbidade ${ }^{2}$, sendo assim um grande problema social e econômico ${ }^{3}$.
Intervenções terapêuticas que atenuam o risco de fraturas são essenciais para reduzir as consequências desta condição ${ }^{4}$. Entre os medicamentos prescritos no tratamento da osteoporose estão os Bifosfonatos (BPs), drogas sintéticas análogas do pirofosfato, um produto normal do metabolismo humano, empregados na terapêutica primária para a prevenção e tratamento da osteoporose sendo também usado para uma variedade de doenças 
ósseas, o mieloma múltiplo, a Doença de Paget, hipercalcemia de malignidade e metástases ósseas ${ }^{5}$.

Atualmente, o tratamento de primeira linha para a osteoporose são os bifosfonatos com nitrogênio, tais como alendronato, risedronato e ibandronato ${ }^{4}$. $\mathrm{O}$ alendronato de sódio é um agente inibidor especifico da reabsorção óssea osteoclástica. Primeiramente ele se fixa na matriz óssea. Posteriormente é assimilado pelos osteoclastos para, em seguida, inibir sua ação ${ }^{5}$.

O uso de BP está associado com a necrose óssea dos maxilares, condição esta, secundária aos mecanismos de ação da droga, resultando em atividades antiosteoclástica e antiangiogênica, alterando 0 metabolismo ósseo, inibindo a reabsorção e diminuindo seu turnover $^{6}$ (renovação óssea).

A osteonecrose da mandíbula relacionada a medicamentos (OMRM) foi descrita pela primeira vez por Marx em 20037. Este fenômeno é caracterizado pela presença do osso exposto ou sondável através de uma fístula extraoral ou intraoral na região maxilofacial por um período superior a 8 semanas nos indivíduos submetidos a medicação anterior ou atual com agentes antireabsortivos ou antiangiogênicos e que não têm história precedente de radioterapia ou doença metastática no osso mandibular ${ }^{8}$.

Este fenômeno ocorre quase que exclusivamente nos ossos gnáticos. Tal evento pode ser explicado devido os maxilares possuírem um maior suprimento sanguíneo e um metabolismo ósseo mais acelerado, relacionado às suas atividades fisiológicas, acarretando uma maior concentração destas drogas nestes ossos. Soma-se a isto, os tratamentos odontológicos invasivos ou injurias locais e a presença de uma mucosa fina os recobrindo ${ }^{5}$.

Os fatores de risco que influenciam no desenvolvimento da osteonecrose estão relacionados com o tipo de $\mathrm{BP}$, duração da terapia, fatores agressores locais, demográficos e sistêmicos, dentre outros ${ }^{9}$.

O diagnóstico da osteonecrose induzida por BP é primariamente baseado na anamnese aprofundada e no exame clínico do paciente ${ }^{10}$, laudos histopatológicos, além de exames complementares como tomografia ${ }^{11}$.

A Associação Americana de Cirurgiões Orais e Maxilofaciais. Classifica a OMRM em estágios $^{11}$ : Em risco - sem osso necrótico aparente em indivíduos que têm sido tratado com bisfosfonatos orais ou intravenosos; Estágio 0 - nenhuma evidência clínica de lesões, mas achados clínicos inespecíficos, alterações radiográficas e sintomas; Estágio 1 osso necrótico exposto ou sondável através de uma fístula, assintomático e sem sinais de infecção; Estágio 2 - osso necrótico exposto ou sondável através de uma fístula associado à infecção, sintomático e eritema na região de exposição com ou sem drenagem purulenta; e estágio 3 - osso necrótico exposto sintomático e infectado acompanhado por alguns dos seguintes itens: fístula extraoral, fraturas patológicas ou osteólise ${ }^{8}$. Isso tem sido muito utilizado para prognóstico e terapia em casos de $\mathrm{OMRM}^{4}$.

A patogênese da OMRM ainda é pouco elucidada, o que dificulta sua prevenção e tratamento ${ }^{11}$. Embora existam muitos protocolos de tratamento OMRM, ainda não há consenso sobre o que é mais eficaz ${ }^{12}$. Atualmente os tratamentos indicados são fundamentados no estadiamento clínico da doença, variando de enxaguatório bucal com clorexidina e antibióticos para desbridamento e ressecção cirúrgica de área afetada ${ }^{8}$.

No entanto, terapias adjuvantes, como o laser terapêutico de baixa intensidade (LLLT) ${ }^{11}$ e terapia fotodinâmica antimicrobiana (PDT), vem sendo utilizadas para prevenção e tratamento de OMRM $^{13}$. O LLLT baseia-se na biomodulação celular, aumentando a proliferação e diferenciação dos osteoblastos ${ }^{14}$, tem efeito antiinflamatório e analgésico ${ }^{15}$ além de promover a formação óssea e a cicatrização dos tecidos moles ${ }^{16}$. A PDT é uma combinação de um agente fotossensibilizante, oxigênio e irradiação luminosa. Que através do uso de corantes fotossensíveis, como azul de metileno, produz espécies reativas de oxigênio causando morte de bactérias no local ${ }^{12,17}$.

Desta maneira, o objetivo deste trabalho é relatar um caso clínico de osteonecrose induzida por bifosfonato em mandíbula em uma paciente que faz uso do alendronato oral para tratamento da osteoporose.

CASO CLÍNICO

Paciente do sexo feminino, 76 anos de idade, melanoderma, portadora de hipertensão, osteoporose e Artrite reumatoide, compareceu a clínica de Estomatologia na Policlínica Odontológica da Universidade do Estado do Amazonas-UEA queixando-se de lesão nodular em região de rebordo alveolar inferior esquerdo, relatando que o processo iniciara havia cerca de quatro meses.

Durante a anamnese, relatou ser portadora de prótese parcial removível inferior e que faz uso de alendronato de sódio, 70 $\mathrm{mg} / \mathrm{semana}$, há mais de 20 anos para 
tratamento de osteoporose. Ao exame intraoral constatou-se lesão nodular séssil, indolor, consistência mole, forma e superfície irregular, cor semelhante à mucosa circunjacente, medindo 1,5 x 0,6 x 0,5 cm (Figura 1).

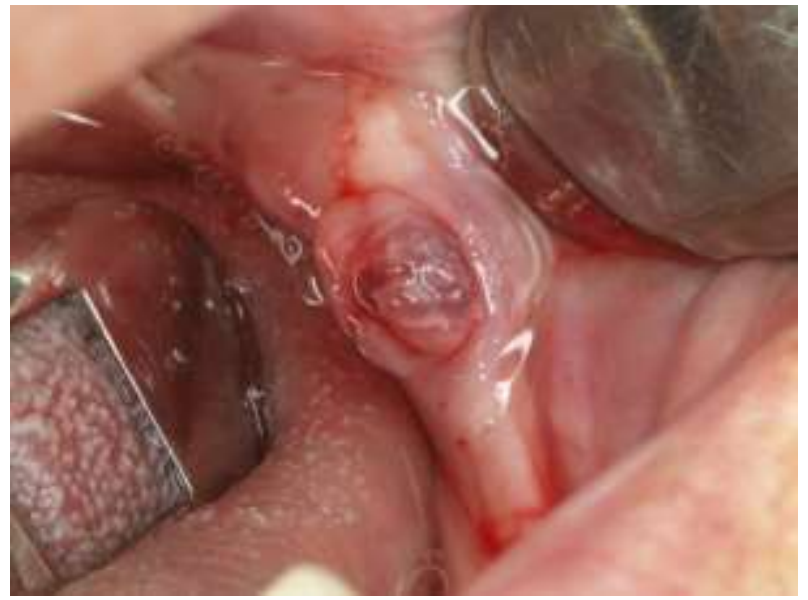

Figura 1: Aspecto clínico da lesão.

Foi solicitada, como exame complementar, tomografia computadorizada para investigar possível origem infecciosa subjacente à lesão superficial. A imagem mostrou área de reabsorção em taça (Figura 2A e 2B).

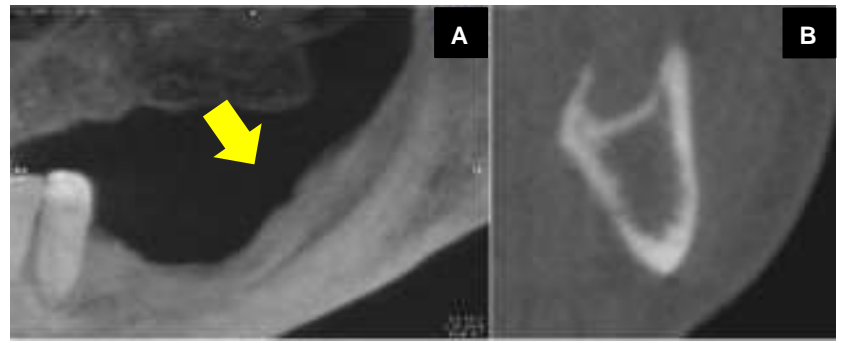

Figura 2: Tomografia computadorizada de mandíbula mostrando área de reabsorção em taça. (A-B).

Realizou-se biópsia excisional da lesão superficial, aspecto clínico de parúlide, sob anestesia de bloqueio dos nervos: alveolar inferior, lingual e bucal esquerdos. Foi realizada excisão de forma elíptica de aproximadamente $1,5 \mathrm{~cm}$, removendo toda a lesão $e$ posteriormente síntese (Figuras 3 a 5).

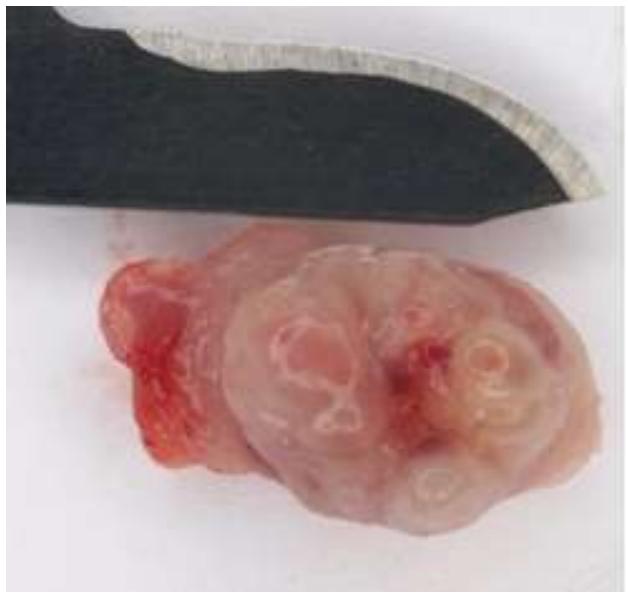

Figura 3: Lesão removida.

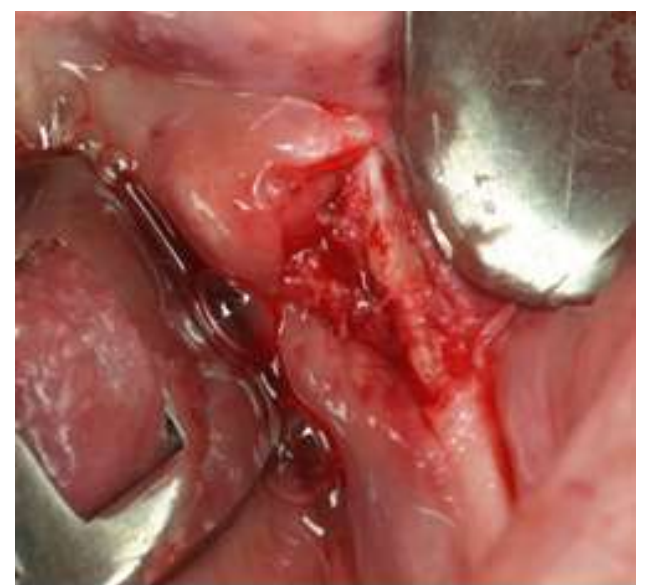

Figura 4: Sítio cirúrgico após a remoção da lesão.

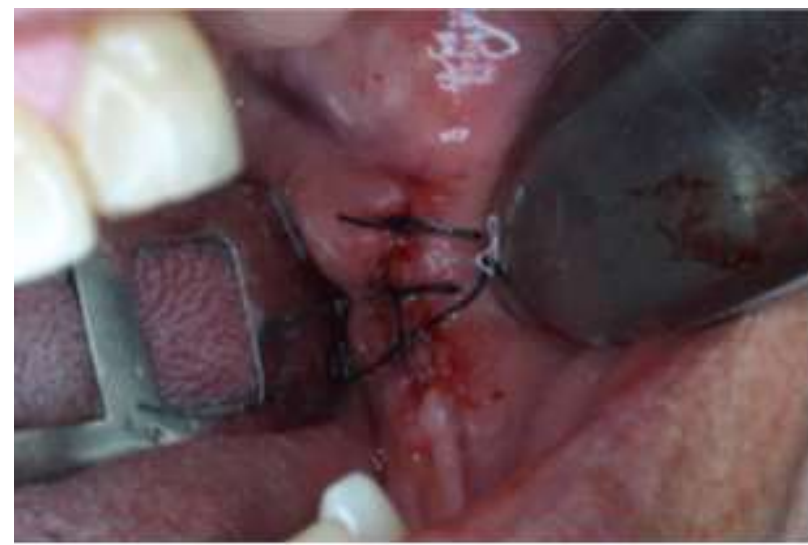

Figura 5: Aspecto final após sutura.

O material coletado foi incluído em solução formalina a $10 \%$ e submetido ao exame histopatológico, onde revelou-se epitélio com áreas hiperplásicas e atróficas, com focos de desorganização por exocitose polimorfonuclear. Destaca-se ainda a presença de pseudocisto córneo e necrose coagulativa (Figura 6).

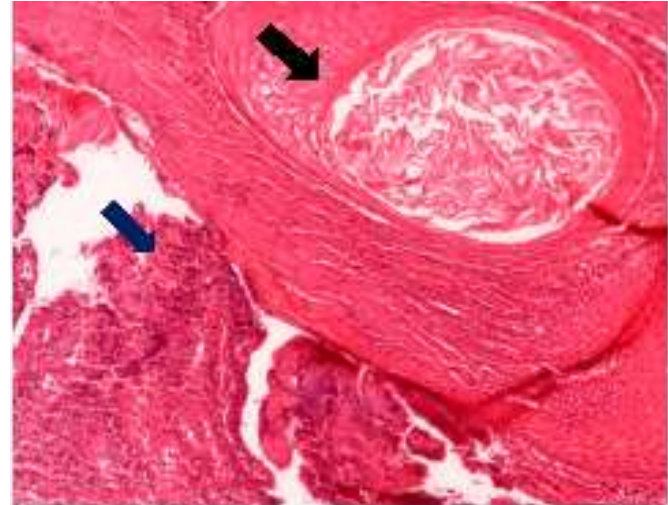

Figura 6: Histopatologia revela presença de pseudocisto córneo (seta preta) e necrose coagulativa (seta azul).

Também foi observado que no tecido conjuntivo, apresentava intenso infiltrado inflamatório leucocitário polimorfonuclear em meio ao exsudato fibrinopurulento. Além de cariorrex e aglomerados microbianos (Figura 7). Diante da anamnese, exames imagenológicos e histopatológico foi fechado o diagnóstico de "osteonecrose induzida por bifosfonato em mandíbula". 
A paciente retornou depois de 7 dias de pós-operatório para remoção da síntese onde foi observado o epitélio em fase de cicatrização (Figura 8).

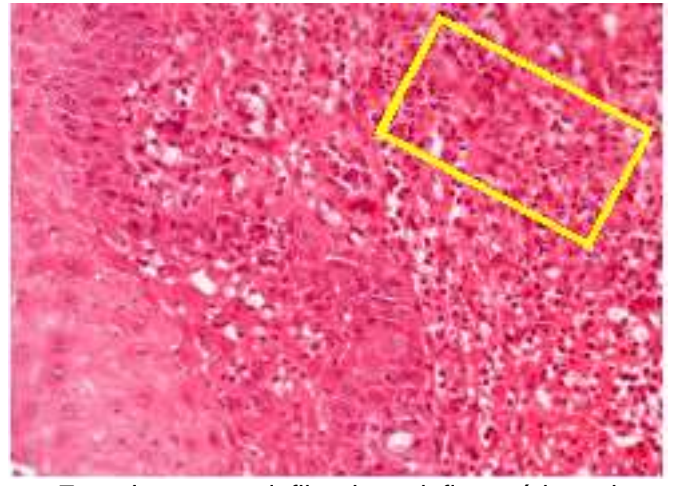

Figura 7: Intenso infiltrado inflamatório leucocitário polimorfonuclear em meio ao exsudato fibrinopurulento (Retângulo amarelo).

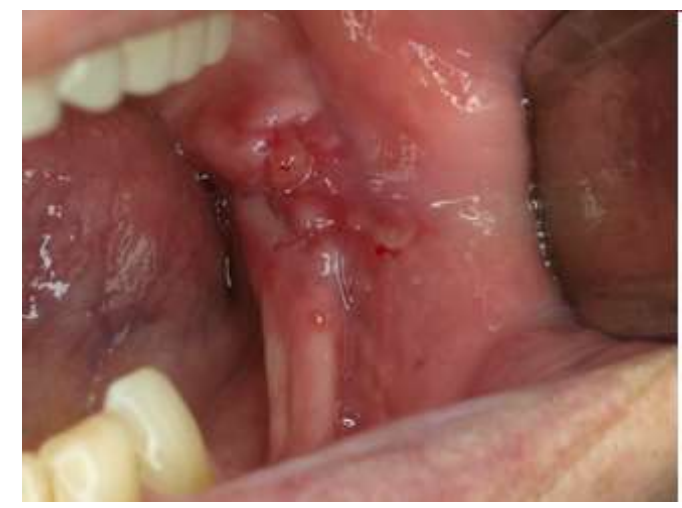

Figura 8: Sítio cirúrgico após 7 dias.

O uso do bisfosfonato não foi interrompido. No primeiro momento 0 tratamento instituído foi remoção cirúrgica da lesão superficial e desgaste protético para 0 alívio do trauma local (Figura 9).

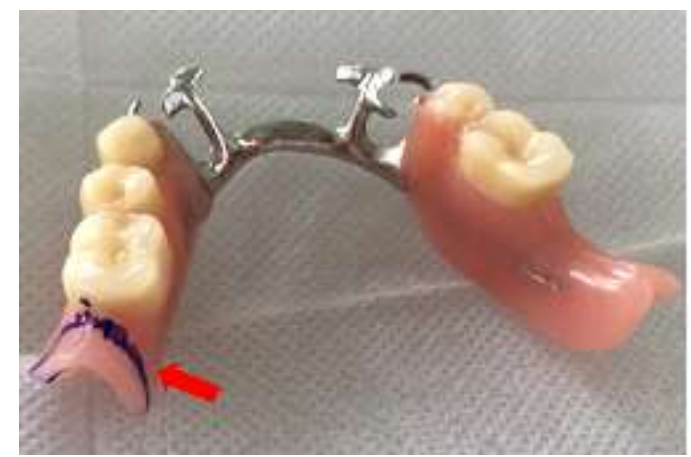

Figura 9: Seleção da área de desgaste (seta vermelha).

A paciente foi acompanhada no pósoperatório, e, após 6 meses de proservação (Figura 10) observava-se rebordo alveolar recoberto com leve eritema, sugerindo solução de continuidade com o tecido ósseo. Então, foi indicada laserterapia de baixa intensidade, vermelho e infravermelho, $3\left(\mathrm{~J} / \mathrm{cm}^{2}\right)$ local.

A paciente não teve recidiva da lesão após 1 ano e 11 meses do tratamento (Figura 11).

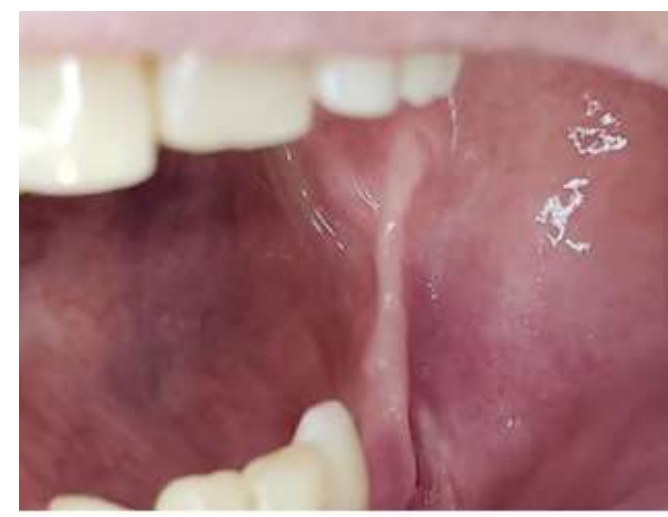

Figura 10: Sítio cirúrgico 6 meses após a biópsia.

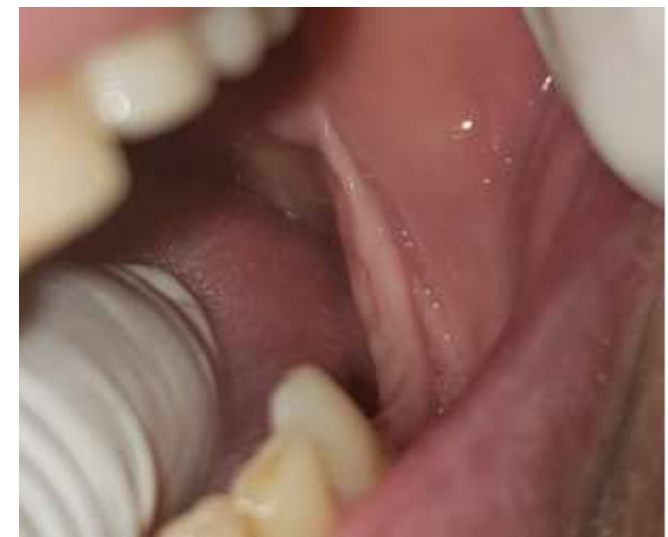

Figura 11: Pós-operatório de 1 ano e 11 meses de proservação. DISCUSSÃO

Ruggiero et $\mathrm{al}^{18}$ estabeleceram uma classificação clínica para lesões com base nos níveis de destruição do osso e os sintomas ${ }^{4}$. De acordo com esse estudo a complicação em questão foi classificada em estágio II.

Parúlide é um tecido de granulação cronicamente inflamado e se organiza como um receptáculo de fístula ${ }^{19}$. A presença clínica da mesma confirmada no laudo histopatológico, mostra a existência de uma infecção de baixa intensidade, esta sintomatologia poderia até estar presente, mas pouco intensa, não percebida pela paciente. A presença de um processo infeccioso crônico no laudo histopatológico de um tecido mole relacionado com esse tecido ósseo que está reabsorvido em taça é um sinal claro de que aconteceu um processo infeccioso relacionado ao osso. A parúlide é sinal de que ocorreu um processo infeccioso que poderia ser dentário, porém a lesão encontrava-se em uma área edêntula, o que justifica fazendo levantamento da história clínica da paciente o processo osteonecrótico pelo uso do bifosfonato. $\mathrm{O}$ uso deste medicamento, as características imagenológicas e os sinais histopatológicos foi o que fechou $o$ diagnóstico.

O tempo médio de exposição ao alendronato de sódio para a ocorrência de OMRM é de $3 \operatorname{anos}^{9,20}$ a 5,7 anos ${ }^{21}$. Neste relato 
de caso, a paciente faz o uso deste fármaco há mais de 20 anos. Estudos que avaliaram a incidência da osteonecrose associada ao uso do alendronato para tratamento da osteoporose, demostraram uma incidência maior em mulheres e com a média de idade superior a 65 anos $^{22,23}$, esse fato deve está relacionado a maior incidência de osteoporose no sexo feminino, o que é atribuído a fatores associados a pós-menopausa ${ }^{5}$.

No caso em questão a paciente apresentava lesão localizada na mandíbula em região de molares. O que corrobora com as informações de que o aumento da prevalência de OMRM é na mandíbula, em particular nas regiões pré-molares e molares, devido, potencialmente, ao menor suprimento de sangue ao tecido ósseo desta área ${ }^{11}$.

Em relação aos fatores de risco para desenvolvimento da OMRM, a exodontia é o fator local mais relatado ${ }^{5}$. No estudo de Sedghizadeh et $\mathrm{al}^{24}$, todos os casos ocorreram após exodontias, o que difere deste. No entanto, alguns casos ocorrem espontaneamente, mas estes são de fato muitas vezes associados com infecção, trauma local protético ou outro trauma $^{25}$. Neste caso, a paciente fazia uso de prótese parcial removível como fator de risco local, e também uso de corticoide para tratamento de artrite reumatoide. Os corticosteroides estão associados a um risco aumentado de OMRM $^{8}$.

O tratamento para indivíduos com diagnóstico definido de OMRM tem como objetivos: controlar a infecção dos tecidos moles e duros, e minimizar a progressão ou ocorrência de necrose óssea para otimizar cicatrização de feridas $^{26}$. A conduta adotada no manejo deste caso foi a exérese da lesão superficial para avaliação histopatológica, desgaste da área de excesso da prótese, onde a mesma foi suspensa até que ocorresse a cicatrização e recobrimento do rebordo alveolar. No retorno a paciente apresentava sinal de não reparação completa e de que a cirurgia não foi completamente resolutiva, então optamos por associá-la à fotobiomodulação com laser de baixa intensidade vermelho e infravermelho que era o que tínhamos disponível na Policlínica Odontológica da Universidade do Estado do Amazonas-UEA, para consolidar essa reparação.

O tratamento convencional nem sempre é eficaz, sendo necessário empregar o uso de terapias adjuvantes ${ }^{11}$. Usamos o laser vermelho com fim de reparar o tecido de superfície que apresentava leve eritema. Enquanto que o laser infravermelho foi indicado com a finalidade de biomodulação do tecido ósseo que se encontra pelo uso de alendronato, hipocelularizado, hipovascularizado e hiporresponsivo. O laser de baixa intensidade vermelho foi utilizado para promover reparos teciduais de lesões superficiais, enquanto o laser infravermelho, possibilita a biomodulação do tecido ósseo, estimulando sua reparação.

CONCLUSÃO

Diante dos protocolos estabelecidos para gestão da osteonecrose por bifosfonato concluímos que a combinação de cirurgia, desgaste protético com fim de reduzir o trauma local e laserterapia de baixa intensidade foi eficaz no tratamento deste caso.

\section{AGRADECIMENTOS}

Ao Serviço de Patologia Oral e Maxilofacial da Universidade do Estado do Amazonas (SEPAT - UEA) na pessoa do Dr. Tiago Novaes Pinheiro. Nosso reconhecimento e gratidão, pela dedicação e colaboração na realização deste trabalho.

REFERÊNCIAS

1. NIH Consensus Development Panel on Osteoporosis Prevention, Diagnosis, and Therapy, March 7-29, 2000: highlights of the conference. South Med J. 2001;94(6):569-73.

2. Sambrook P, Cooper C. Osteoporosis. Lancet. 2006;367(9527):2010-18.

3. McCadden L, Leonard CG, Primrose WJ. Bisphosphonate-induced osteonecrosis of the ear canal: our experience and a review of the literature. J Laryngol Otol. 2018;132(4):372.

4. Santos PSS, Oliveira MA, Felix VB. Bisphosphonate-induced maxillofacial osteonecrosis in osteoporotic individuals. Rev bras ortop. 2011;46(5):495-99.

5. Morais EF, Macedo RAP, Lira JAS, Arruda MDLS. Osteonecrose dos maxilares associado ao uso de alendronato oral em paciente sob tratamento de osteoporose. Rev Catussaba. 2016;5(1):21-9.

6. Ruggiero SL, Woo SB. Biophosphonate-related osteonecrosis of the jaws. Dent Clin North Am. 2008;52(1):111-28.

7. Marx RE. Pamidronate (Aredia) and zoledronate (Zometa) induced avascular necrosis of the jaws: a growing epidemic. J Oral Maxillofac Surg. 2003;61(9):1115-17.

8. Ruggiero SL, Dodson TB, Fantasia J, Goodday $\mathrm{R}$, Aghaloo $\mathrm{T}$, Mehrotra $\mathrm{B}$ et al. American Association of Oral and Maxillofacial Surgeons Position Paper on Medication-Related Osteonecrosis of the Jaw - 2014 Update. J Oral Maxillofac Surg. 2014;72(10):1938-56.

9. Marx RE, Sawatari Y, Fortin M, Broumand V. Bisphosphonate-induced exposed bone (osteonecrosis/osteopetrosis) of the jaws: risk factors, recognition, prevention, and treatment. 
J Oral Maxillofac Surg. 2005;63(11):1567-75.

10. Brozoski MA, Traina AA, Deboni MCZ, Marques MM, Naclério-Homem MDG. Osteonecrose maxilar associada ao uso de bisfosfonatos. Rev bras reumatol. 2012;52(2):265-70.

11. Rodríguez-Sánchez MDP, Statkievicz C, MelloNeto JM, Toro LF, Bassi APF, Garcia VG et al. The Effectiveness of the Low-Level Laser, Antibiotic and Surgical Therapy in the Treatment of Medication-Related Osteonecrosis of the Jaws: A Case Report. J Lasers Med Sci. 2020;11(1):98-103.

12. Lee JY, Kim IR, Park BS, Kim YD, Chung IK, Song JM, et al. Effect of low-level laser therapy on oral keratinocytes exposed to bisphosphonate. Lasers Med Sci. 2015;30(2): 635-43.

13. Tartaroti NC, Marques MM, Naclério-Homem MG, Migliorati CA, Deboni MCZ. Antimicrobial photodynamic and photobiomodulation adjuvant therapies for prevention and treatment of medication-related osteonecrosis of the jaws: Case series and long-term follow-up. Photodiagnosis Photodyn Ther. 2020;29: 101651.

14. Oliveira FA, Matos AA, Santesso MR, Tokuhara CK, Leite AL, Bagnato VS, et al. Low intensity lasers differently induce primary human osteoblast proliferation and differentiation. J Photochem Photobiol B. 2016;163:14-21.

15. Spanemberg JC, Figueiredo MA, Cherubini K, Salum FG. Low-level laser therapy: a review of its applications in the management of oral mucosal disorders. Altern Ther Health Med. 2016;22(6):24-31.

16. Medeiros ML, Araújo-Filho I, Silva EMN, Queiroz WSS, Soares CD, Carvalho MGF, et al. Effect of low-level laser therapy on angiogenesis and matrix metalloproteinase-2 immunoexpression in wound repair. Lasers Med Sci. 2017;32(1):35-43.

17. Rosa LP, Silva FC, Nader SA, Meira GA, Viana MS. Effectiveness of antimicrobial photodynamic therapy using a $660 \mathrm{~nm}$ laser and methyline blue dye for inactivating Staphylococcus aureus biofilms in compact and cancellous bones: An in vitro study. Photodiagnosis Photodyn Ther. 2015;12(2): 276-81.

18. Ruggiero SL, Fantasia J, Carlson E. Bisphosphonate-related osteonecrosis of the jaw: background and guidelines for diagnosis, staging and management. Oral Surg Oral Med Oral Pathol Oral Radiol Endod. 2006;102(4): 433-41.

19. Neville BW, Damm DD, Allen CM, Bouquet JE. Patologia Oral e Maxilofacial. 3.ed. Rio de Janeiro: Elsevier; 2009.

20. Ruggiero SL. American Association of Oral and Maxillofacial Surgeons: American Association of Oral and Maxillofacial Surgeons position paper on bisphosphonate-related osteonecrosis of the jaws-2009 update. J Oral Maxillofac Surg. 2009;67(5):2-12.

21. Marx RE, Cillo JE Jr, Ulloa JJ. Oral bisphosphonate-induced osteonecrosis: risk factors, prediction of risk using serum CTX testing, prevention, and treatment. $\mathrm{J}$ Oral Maxillofac Surg. 2007;65:2397-410.

22. Lin TC, Yang CY, Yang YHK, Lin SJ. Incidence and risk of osteonecrosis of the jaw among the Taiwan osteoporosis population. Osteoporosis International. 2014;25(5):1503-11.

23. Yarom N, Yahalom R, Shoshani Y, Hamed W, Regev E, Elad S. Osteonecrosis of the jaw induced by orally administered bisphosphonates: incidence, clinical features, predisposing factors and treatment outcome. Osteoporos Int. 2007;18(10):1363-70.

24. Sedghizadeh PP, Stanley K, Caligiuri M, Hofkes S, Lowry B, Shuler CF. Oral bisphosphonate use and the prevalence of osteonecrosis of the jaw: an institutional inquiry. J Am Dent Assoc. 2009;140(1):61-6.

25. Iglesias JE, Salum FG, Figueiredo MA, Cherubini K. Important aspects concerning alendronate-related osteonecrosis of the jaws: a literature review. Gerodontology. 2015;32(3): 169-78.

26. Beth-Tasdogan NH, Mayer B, Hussein H, Zolk $O$. Interventions for managing medicationrelated osteonecrosis of the jaw. Cochrane Database of Syst Rev. 2017;10(10):CD012432

\section{CONFLITO DE INTERESSES}

Os autores declaram não haver conflitos de interesse

AUTOR PARA CORRESPONDÊNCIA

\section{Maria Santos da Silva}

Rua Nova Luzitânia, $n^{\circ}$ 15, Bairro Crespo, 69073-187, Manaus-AM, Brasil

E-mail:mss.odo16@uea.edu.br
Submetido em 11/07/2021 Aceito em 01/09/2021 